Bond University

Research Repository

\title{
Assessing the variation in the load that produces maximal upper-body power
}

Argus, Christos K.; Gill, Nicholas D.; Keogh, Justin W L; Hopkins, Will G.

Published in:

Journal of Strength and Conditioning Research

DOI:

10.1519/JSC.0b013e318295d1c9

Licence:

Other

Link to output in Bond University research repository.

Recommended citation(APA):

Argus, C. K., Gill, N. D., Keogh, J. W. L., \& Hopkins, W. G. (2014). Assessing the variation in the load that produces maximal upper-body power. Journal of Strength and Conditioning Research, 28(1), 240-244. https://doi.org/10.1519/JSC.0b013e318295d1c9

\footnotetext{
General rights

Copyright and moral rights for the publications made accessible in the public portal are retained by the authors and/or other copyright owners and it is a condition of accessing publications that users recognise and abide by the legal requirements associated with these rights.
}

For more information, or if you believe that this document breaches copyright, please contact the Bond University research repository coordinator. 


\section{Individual variation in peak power 1}

Title: Assessing the variation in the load that produces maximal upper-body power.

Running head: Assessing variation in peak power. 
Individual variation in peak power 2

\section{ABSTRACT}

Substantial variation in the load that produces maximal power has been reported. It has been suggested that the variation observed may be due to differences in subject physical characteristics. Therefore the aim of this study was to determine the extent in which anthropometric measures correlate to the load that produces maximal power. Anthropometric measures (upper-arm length, forearm length, total arm length, upper-arm girth) and bench press strength were assessed in 26 professional rugby union players. Peak power was then determined in the bench press throw exercise using loads of 20 to $60 \%$ of one repetition maximum (1RM) in the bench press exercise. Maximal power occurred at $30 \pm 14 \% 1 \mathrm{RM}$ (mean $\pm \mathrm{SD}$ ). Upper-arm length had the highest correlation with the load maximizing power: -0.61 (90\% confidence limits -0.35 to -0.78 ), implying loads of 22 vs. $38 \% 1 \mathrm{RM}$ maximize power for players with typically long vs. short upper-arm length. Correlations for forearm length, total arm length and upper-arm girth to the load that maximized power were -0.29 (0.04 to -0.57$),-0.56(-0.28$ to -0.75$)$, and 0.29 (0.04 to -0.57$)$, respectively. The relationship between $1 \mathrm{RM}$ and the load that produced maximal power was $r=-0.23(0.10$ to -0.52$)$. The between-subject variation in the load that maximised power observed $(\mathrm{SD}= \pm 14 \% 1 \mathrm{RM})$ may have been due to differences in anthropometric characteristics, and absolute strength and power outputs. Indeed, athletes with longer limbs and larger girths, and greater maximal strength and power outputs utilised a lower percentage of 1RM loads to achieve maximum power. On the basis of these substantial effects of body build, we recommend individual assessment of the load that maximizes power output.

Key words: ELITE ATHLETES, BENCH THROW, BETWEEN-SUBJECT VARIATION, PMAX. 
Individual variation in peak power 3

\section{INTRODUCTION}

Maximal power output is produced when an optimal level of both force and velocity is achieved (28). For example during a ballistic exercise, if the external load is too large, velocity may be compromised; whereas, if the external load is too light, force may be compromised, and in both instances result in sub-optimal power production. The load that maximises power has been repeatedly assessed (e.g. 2, 5, 6, 7, 9-11, 16, 17, 20, 25), with large variation in the optimal load reported both between separate investigations, and also between-subjects within investigations. Specifically, for the upper-body, a range of $15-70 \%$ one repetition maximum (1RM) has been suggested to produce maximal power $(5,6,9,12,25)$. The variation in findings is likely due to differences in methodologies used (9) and subject characteristics $(6,28)$.

Bevan and colleagues (9) highlighted that the large variation in the optimal load was likely due to methodological differences such as, data collection techniques, exercises performed, strength levels of the subjects, and the reporting of either mean or peak power. In order to standardise the methodological design, Bevan and colleagues (9) determined that a protocol which included a flat-bench bench-throw, where peak power was recorded via a linear position transducer in strength trained athletes (professional Rugby Union players) would allow better comparison to previous literature. It was reported that a load equalling $30 \%$ of $1 \mathrm{RM}$ allowed maximal power to be produced (9). However, by assessing the load that produces maximal power using a different method to previously outlined in the literature, Bevan and colleagues (9) may have added to the variation in findings reported. Indeed, the study by Baker and colleagues (6), recruited trained athletes, but assessed mean power output, and reported that maximal power was produced at $55 \%$ of 1RM. Whereas, Newton and colleagues (25) assessed peak power, but recruited sport 
science students, and reported that maximal power was produced at 15\% and 30\% of 1RM. As such, to minimise variation in the load that produces maximal power reported between studies, methodologies need to be replicated.

Regardless of methods used, authors have also reported a considerable between-subject variation in the load that maximises power within studies that may be due to differences in subject characteristics. For example, Baker and colleagues (6) reported a standard deviation of 5.3\% either side of the mean bench press-throw power output (54.9\%1RM) in rugby league players. If one were to extrapolate findings to include the whole population tested (i.e. three standard deviations or $>99.74 \%$ of subjects), maximal power production would range between $31 \underline{39}$ 7971\%1RM. Similarly, Bevan and colleagues (9) reported that while 30\% 1RM produced maximal power for the entire group, there were no significant differences between power outputs at 30,40, or 50\% 1RM. In an attempt to elucidate a possible mechanism for the between-subject variation, Siegal and colleagues (27) performed a regression analysis to compare muscle fibre composition to the percentage 1 RM that produced maximal power in a bench throw and jump squat exercise in 15 untrained males. However, no significant relationships were observed. Less invasive measures, such as the rRelationships between the load that produces maximal power, and maximal strength, limb length or girth measurement may help to identify some of the between-subject variation. Indeed, Baker (5) reported that stronger athletes use a lower percentage of 1RM to produce maximal power compared to their less-strong counterparts. It has also been reported that athletes with more muscular limbs may have greater lifting capacity (18). However, the effect of anthropometric characteristics on the load that produces maximal power has not been established. 
Therefore, the aim of this investigation was to determine the extent in which anthropometric measures correlate to the load that produces maximal power. In order to minimise variation in findings between studies, the methods outlined by Bevan and colleagues (9) were used.

\section{METHODS}

\section{Experimental Approach to the Problem}

In order to determine the extent in which anthropometric measures correlate to the load that produces maximal power, professional Rugby Union players were assessed for upper-body maximal strength and power across three sessions. During the first session, players were assessed for bench press strength and anthropometric measures (body mass, height, upper-arm girth, upper-arm length, forearm length). During the second and third session, players were assessed for peak power during a ballistic bench throw at a range of loads $(20,30,40,50,60 \% 1 \mathrm{RM}$; Table 1). Power testing was split into two separate sessions to limit fatigue. Each session was separated by 24 hours. Peak power measured in a bench throw with a linear position transducer was selected in an attempt to replicate the assessment methods in the study by Bevan and colleagues (9).

Insert Table 1 about here

\section{Subjects}

Twenty six elite rugby union players from a Super 14 professional Rugby Union team during the

pre-season phase of their campaign volunteered to take part in this study (mean $\pm \mathrm{SD}$; age, 24.0 
\pm 2.3 years; height, $183.6 \pm 2.9 \mathrm{~cm}$; mass, $101.1 \pm 10.1 \mathrm{~kg}$ ). Each player had undergone at least two years of intensive and regular resistance training exercise, and was well familiarised with all the testing procedures. Players were informed of the experimental risks and signed an informed consent document prior to the investigation. The investigation was approved by an Institutional Review Board for use of Human subjects (Auckland University of Technology Ethics Committee).

\section{Procedures}

\section{Anthropometric Measures}

International Society for the Advancement of Kinanthropometry (ISAK) protocols were used to determine the anthropometric profile of the rugby players (27). Measurement included body mass, standing height, upper-arm girth, upper-arm length (acromiale-radiale length), and forearm length (radiale-stylion length). Total arm length was considered to be the sum of upper-arm and forearm length.

\section{Strength}

Maximal strength was assessed using the bench press exercises using methods previously outlined $(1,3)$. Briefly, following three sub-maximal sets of bench press (approximately $60 \%$ $80 \% 90 \% 1 \mathrm{RM}$ ), each player then performed one set to failure of one to four repetitions. The bench press was performed using free weights. Three minutes rest was allowed between each set. The final set was used to predict the players' one repetition maximum (1RM). 
The following equation was used to predict bench press 1RM (21). This equation is a valid measure of 1RM strength as it has been shown to have a correlation between actual and predicted 1RM of $r=0.993(22)$ :

$$
1 \mathrm{RM}=(100 \times \text { weight }) /(101.3-(2.67123 \times \text { reps }))
$$

\section{Bench Throw}

Upper-body power was assessed using a bench throw exercise performed in a Smith machine. Players warmed up with one set of 10 repetitions of press ups, one set of five repetitions of clap press ups, and two sets of three repetitions of bench throw at $30 \%$ and $50 \%$ of their 1RM bench press. Players then completed one set of four repetitions of the bench throw at $20 \%, 30 \%, 40 \%$, $50 \%$ or $60 \% 1 \mathrm{RM}$ bench press. Players used a self-selected hand position and were instructed to lower the bar to approximately a $90^{\circ}$ angle at the elbow. Players were then required to throw the bar vertically and explosively as possible trying to propel the bar for maximum height $(3,24)$. Following attainment of maximal height, and on the downward phase, the bar was caught by two 'spotters' and lowered gently into the subject's hands-. Five minutes rest separated each set.

The power produced during each bench throw repetition was quantified with a Gymaware ${ }^{\mathrm{TM}}$ optical encoder $(50 \mathrm{~Hz}$ sample period with no data smoothing or filtering; Kinetic Performance Technology, Canberra, Australia) using the methods described elsewhere (13). Quantification of the power produced during the bench throw was calculated using the bar mass (14).

\section{Statistical Analyses}


To estimate the load that maximized mechanical power output in the upper-body, a quadratic was fitted to each player's power output (in Watts) and load (\% of 1RM). The goodness of fit of the quadratic was expressed as an overall correlation coefficient $\left(\mathrm{R}^{2}\right)$ calculated by subtracting the total variance from the error variance to determine the variance explained by the model. The variance explained was then divided by the total variance to give $\mathrm{R}^{2}$. Findings were discussed as means and standard deviations.

In addition to fitting a quadratic, standardised differences of the mean were used to assess magnitudes of effects between each individual load assessed by dividing the differences by the appropriate between-athlete standard deviation. Standardised changes of $<0.19,0.19-0.59,0.60-$ $1.19,1.20-1.99$, and $>2.0$ were interpreted as trivial, small, moderate, large and very large effects, respectively $(8,19)$. To make inferences about the true (large-sample) value of an effect, the uncertainty in the effects were expressed as $90 \%$ confidence limits. An effect was deemed unclear if its confidence limits overlapped the thresholds for both the smallest positive and negative effect.

Pearsons correlation coefficients (and 90\% confidence limits) were also calculated between a subjects \%1RM that produced maximal power, and strength and anthropometric measures. Correlations of $<0.09,0.10-0.29,0.30-0.49,0.50-0.69,0.70-0.89,0.90-0.99$, and 1.00 , were interpreted as trivial, small, moderate, large, very large, nearly perfect, and perfect, respectively (19). An effect was deemed unclear if its confidence limits overlapped the thresholds for both the smallest positive and negative correlation. 
The interclass correlation (ICC) and coefficient of variation (CV) for bench throw at $30 \%$ and $50 \%$ of $1 \mathrm{RM}$ bench press were assessed in our laboratory using a similar population and were 0.932 and $5.9 \%$, and 0.900 and $5.0 \%$, respectively. All test-retest reliabilities were assessed seven days apart. Validity of the Gymaware ${ }^{\mathrm{TM}}$ optical encoder has been previously reported elsewhere (13). The sample size for this investigation was limited to the number of players in the squad. All players in the squad were included and therefore no more players could be obtained.

\section{RESULTS}

The mean predicted $1 \mathrm{RM}$ bench press was $121.7 \mathrm{~kg}( \pm 19.2 \mathrm{~kg})$. The estimated upper-body peak power was $1298 \mathrm{~W}( \pm 292 \mathrm{~W})$ and occurred at $30.2 \%( \pm 13.6 \%) 1 \mathrm{RM}$ bench press (mean goodness of fit $\mathrm{R}^{2}=0.72$ ) (Figure 1 ). Peak power at $30 \%$ of $1 \mathrm{RM}$ bench press was found to result in greater (small to moderate effect size) peak power than all other intensities assessed. Of the five loads assessed, 19 of the 26 players produced the greatest upper-body peak power at $30 \%$ 1RM bench press.

Correlations between the percentage of 1RM that produced peak power and upper-arm length, forearm length, total arm length, and upper-arm girth were $r=-0.61$ (90\% confidence limits 0.35 to -0.78$),-0.29$ (0.04 to -0.57$),-0.56(-0.28$ to -0.75$)$, and -0.29 (0.04 to -0.57$)$, respectively. The largest relationship of $\mathrm{r}=-0.61$ between upper-arm length and the load that maximises power, suggests that a subject with a typically shorter upper-arm length (1SD below the mean) produced maximal power at 38\%1RM; while a typically longer upper-arm subject (1SD above the mean) produced maximal power at 22\%1RM. Although a very large correlation between bench press strength and estimated peak power was found ( $\mathrm{r}=0.76 ; 0.58$ to 0.87 ), only a small- 
unclear correlation between bench press strength and the percentage of 1RM that produced peak power was observed $(\mathrm{r}=-0.23 ; 0.10$ to -0.52$)$. Additionally, there was a small-unclear correlation between absolute power and the percentage of 1RM that produced peak power $(\mathrm{r}=-$

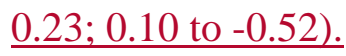

Insert Figure 1 about here

\section{DISCUSSION}

The purpose of this investigation was to determine the extent in which anthropometric measures correlate to the load that produces maximal power using the methods outlined by Bevan and colleagues (9). Small to large correlations ranging from $r=-0.29$ (forearm length and upper-arm girth) to -0.61 (upper-arm length) were observed and thus, the shared variance of these measures $\left(\mathrm{r}^{2}\right.$ as a $\left.\%\right)$ suggest that $8-37 \%$ of the between-subject variation may be explained by these anthropometric descriptors of the upper limb. More specifically, players with typically long or short upper-arm length (1SD from the mean) varied by $\pm 8 \% 1 \mathrm{RM}$ in the load that produced maximal power. Whilst players with typically long or short forearm length or upper-arm girth varied by $\pm 4 \% 1 \mathrm{RM}$ in the load that produced maximal power. These findings are of particular importance to practitioners when prescribing training loads to larger groups of players whereby greater within-athlete variation in arm segment lengths is likely.

The upper-arm and total arm length resulted in the strongest relationships between the percentage of 1RM that produced maximal power. The negative correlations associated with these measures suggest that subjects with longer upper-arm and total arm length produced their 
maximal power at a lower percentage of 1RM, with the opposite being true for those with shorter limb lengths. Interestingly, our results showed that athletes with larger upper-arm girth also had a negative correlation with the load that produced maximal power. We re-analysed some of the data and noted that those with longer upper-arms typically had larger girths ( $\mathrm{r}=0.42)$; and both upper-arm length and upper-arm girth were positively correlated to maximal strength ( $\mathrm{r}=0.34$ and

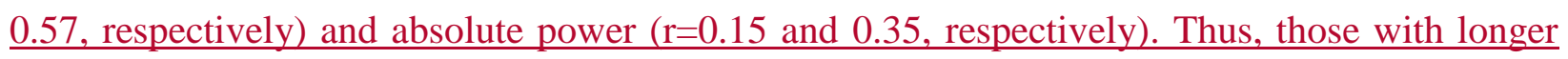
and bigger upper-arms, as a generalisation, were stronger and more powerful. Furthermore, our results showed there were small, albeit unclear, negative relationships with the load that produces maximal power and absolute strength and power. These findings suggest that those with higher strength and absolute power produced maximal power at a lower percent of 1RM. These findings are also in line with previous findings by Baker (5) who reported that stronger athletes use a significantly lower percentage of 1RM to produce maximal power compared to their less-strong counterparts. Therefore, the between-subject variation in the load that produces maximal power may be due to differences in (a combination of) anthropometric characteristics and absolute strength and power outputs.

Upper-body peak power occurred at 30\% 1RM bench press and was similar to that reported by Bevan and colleagues (9) and Newton and colleagues (26), but lower than previously reported peak power outputs which occurred between $40 \%-70 \%$ of $1 \mathrm{RM}$ bench press $(5,6,12)$. It is likely that the difference in findings was due to methodologies used which have been rigorously discussed elsewhere $(2,5-7,9-11,16,17,20,25)$. One potential reason for the lower load observed in the present study is the use of assessing peak power rather than mean power. Previous authors have reported maximal mean power to be achieved at a $10-15 \%$ higher 1 RM 
when compared to maximal peak power $(12,25)$. Indeed, if maximal power was achieved at a $15 \%$ higher 1RM load in the current study (approximately 45\%1RM), it would be consistent with previous literature which recruited a similar athletic population (professional Rugby League athletes; 40\%-60\%1RM) (4-6). It has been previously suggested that when reporting power-load relationships, peak power, rather than mean power should be reported due to its larger relationship with athletic performance (14). Indeed, Marques and colleagues (23) reported that throwing velocity in team-handball players was significantly correlated to peak bench throw power in two of the three loads assessed; whereas, mean power was not significantly correlated with any loads measured. Additionally, Harman and colleagues (15) reported a correlation of $\mathrm{r}=$ $\underline{0.88 \text { between vertical jump height and peak power, but only a correlation of } r=0.54 \text { between }}$ mean power and jump height.

\section{PRACTICAL APPLICATIONS}

When methods are replicated, the average percentage of 1RM strength that produced maximal power in a group of rugby players in the present study can be reproduced and is comparable to previous literature. However, relatively large individual variation is still observed, and is in part due to between-subject differences in anthropometric characteristics and absolute strength and power outputs. Indeed ${ }_{2}$ athletes with longer limbs and larger girths, and greater maximal strength and power outputs utilise a lower percentage of 1RM loads to achieve maximum power. On the basis of these findings, it is recommended that all subjects be individually assessed to determine the load that produces maximal power. 


\section{REFERENCES}

1. Argus CK, Gill N, Keogh J, Hopkins WG, and Beaven CM. Effects of a short-term preseason training programme on the body composition and anaerobic performance of professional rugby union players. J Sports Sci 28: 679-686, 2010.

2. Argus CK, Gill ND, Keogh JWL, and Hopkins WG. Assessing lower-body peak power in elite rugby-union players. J Strength Cond Res 25: 1616-1621, 2011.

3. Argus CK, Gill ND, Keogh JWL, Hopkins WG, and Beaven CM. Changes in strength, power and steroid hormones during a professional rugby union competition. $J$ Strength Cond Res 23: 1583-1592, 2009.

4. Baker D. Comparison of maximum upper body strength and power between professional and college-aged rugby league football players. J Strength Cond Res 15: 30-35, 2001.

5. Baker D. A series of studies on the training of high-intensity muscle power in rugby league football players. J Strength Cond Res 15: 198-209, 2001.

6. Baker D, Nance S, and Moore M. The load that maximizes the average mechanical power output during explosive bench press throws in highly trained athletes. J Strength Cond Res 15: 20-24, 2001.

7. Baker D, Nance S, and Moore $M$. The load that maximizes the average mechanical power output during jump squats in power-trained athletes. J Strength Cond Res 15: 92-97, 2001.

8. Batterham AM and Hopkins WG. Making meaningful inferences about magnitudes. Int J Sports Physiol Perf 1: 50-57, 2006.

9. Bevan HR, Bunce PJ, Owen NJ, Bennett MA, Cook CJ, Cunningham DJ, Newton RU, and Kilduff LP. Optimal loading for the development of peak power output in professional rugby players. J Strength Cond Res 24: 43-47, 2010.

10. Cormie P, Grant OM, Triplett NT, and McBride JM. Optimal loading for maximal power output during lower-body resistance exercises. Med Sci Sports Exerc 39: 340-349, 2007.

11. Cormie P, McBride JM, and McCaulley GO. Power-time, force-time, and velocity-time curve analysis during the jump squat: Impact of load. J Appl Biomech 24: 112-120, 2008.

12. Cronin J, McNair PJ, and Marshall RN. Developing explosive power: a comparison of technique and training. Journal of Science and Medicine in Sport 4: 59-70, 2001.

13. Drinkwater EJ, Galna B, McKenna MJ, Hunt PH, and Pyne DB. Validation of an optical encoder during free weight resistance movements and analysis of bench press sticking point power during fatigue. J Strength Cond Res 21: 510-517, 2007.

14. Dugan EL, Doyle TLA, Humphries B, Hasson CJ, and Newton RU. Determining the optimal load for jump squats: A review of methods and calculations. J Strength Cond Res 18: 668-674, 2004.

15. Harman EA, Rosenstein MT, Frykman PN, and Rosenstein RM. The effects of arms and countermovement on vertical jumping. Med Sci Sports Exerc 22: 825-833, 1990.

16. Harris NK, Cronin JB, and Hopkins WG. Power outputs of a machine squat-jump across a spectrum of loads. J Strength Cond Res 21: 1260-1264, 2007.

17. Harris NK, Cronin JB, Hopkins WG, and Hansen KT. Squat jump training at maximal power loads vs. heavy loads: effect on sprint ability. J Strength Cond Res 22: 1742-1749, 2008.

18. Hart CL, Ward TE, and Mayhew JL. Anthropometric correlates of bench press performance following resistance training. Res Sports Med: Intl J 2: 89-95, 1991. 
19. Hopkins WG, Marshall SW, Batterham AM, and Hanin J. Progressive statistics for studies in sports medicine and exercise science. Med Sci Sports Exerc 41: 3-12, 2009.

20. Kaneko M, Fuchimoto T, Toji H, and Suei K. Training effect of different loads on the force-velocity relationship and mechanical power output in human muscle. Scandinavian Journal of Sports Sciences 5: 50-55, 1983.

21. Lander J. Maximums based on reps. National Strength and Conditioning Association 6: 60-61, 1985.

22. LeSuer DA, McCormick JH, Mayhew JL, Wasserstein RL, and Arnold MD. The accuracy of prediction equations for estimating 1-RM performance in the bench press, squat, and deadlift. J Strength Cond Res 11: 211-213, 1997.

23. Marques MC, van den Tillaar R, Vescovi JD, and Gonzalez-Badillo JJ. Relationship between throwing velocity, muscle power, and bar velocity during bench press in elite handball players. Int J Sports Physiol Perf 2: 414, 2007.

24. Newton RU, Kraemer WJ, Hakkinen K, Humphries BJ, and Murphy AJ. Kinematics, kinetics, and muscle activation during explosive upper body movements. J Appl Biomech 12: 31-43, 1996.

25. Newton RU, Murphy AJ, Humphries BJ, Kraemer WJ, and Hakkinen K. Influence of load and stretch shortening cycle on the kinematics, kinetics and muscle activation that occurs during explosive upper body movements. Eur J Appl Physiol 75: 333-342, 1997.

26. Newton RU, Murphy AJ, Humphries BJ, Wilson GJ, Kraemer WJ, and Hakkinen K. Influence of load and stretch shortening cycle on the kinematics, kinetics and muscle activation that occurs during explosive upper-body movements. Eur J Appl Physiol Occ Physiol 75: 333-342, 1997.

27. Norton K, Whittingham N, Carter L, Kerr D, Gore C, and Marfell-Jones M. Measurement techniques in anthropometry, in: Anthropometrica K Norton, T Olds, eds. Marrackville: UNSW Press., 1996, pp 25-75.

28. Siegel JA, Gilders RM, Staron RS, and Hagerman FC. Human muscle power output during upper- and lower-body exercises. J Strength Cond Res 16: 173-178, 2002.

\section{ACKNOWLEDGEMENTS}

The results of the present study do not constitute endorsement by the NSCA. 
Individual variation in peak power 15

\section{Figure Legends}

Figure 1. Bench throw peak power at a spectrum of intensities in elite rugby union players. RM, Repetition maximum. $\mathrm{n}=26 .{ }^{*}$, denotes small to moderate differences (effect size) between $30 \%$ and all other loads. 
Individual variation in peak power 16

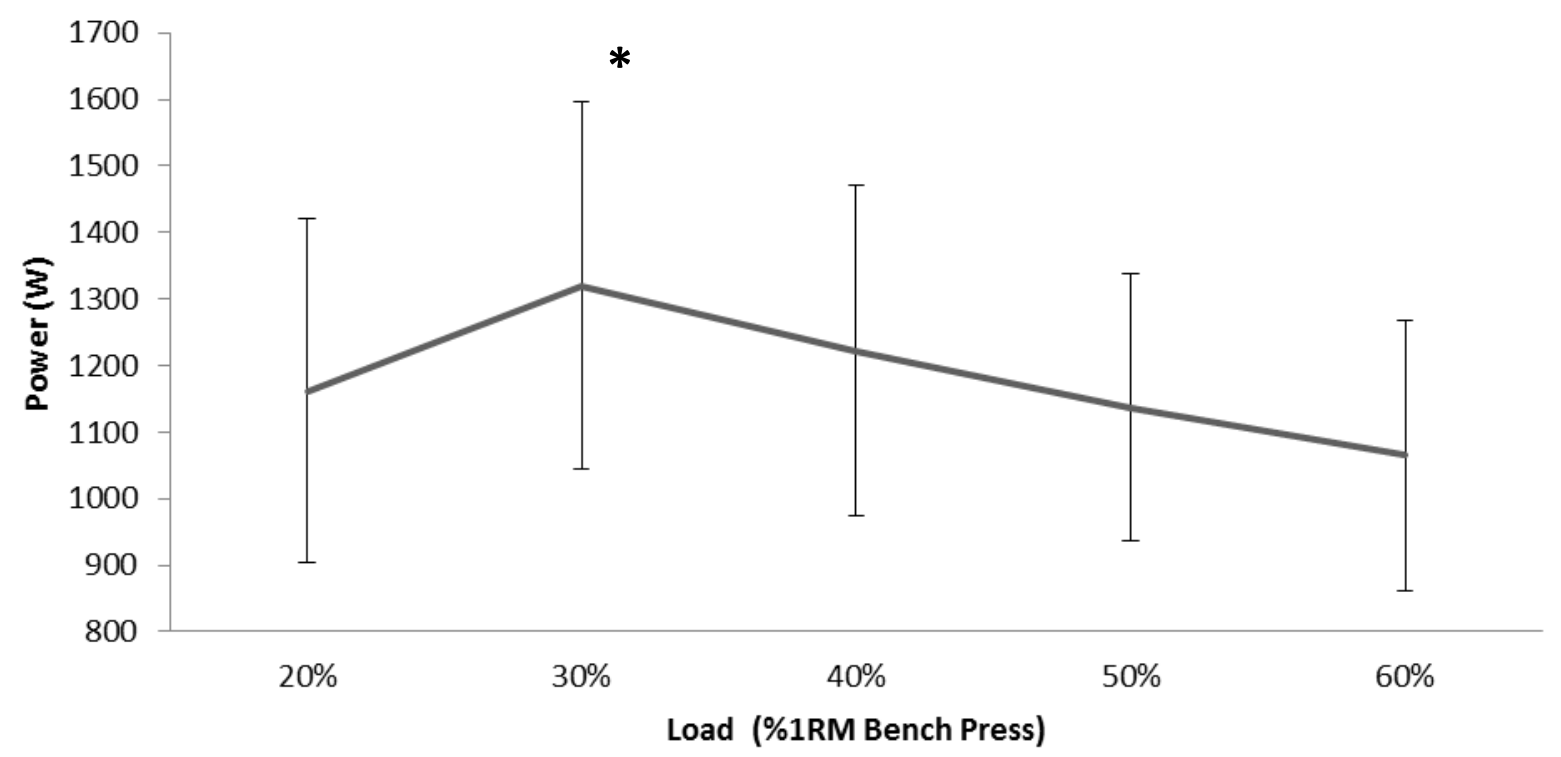

Figure 1. Bench throw peak power at a spectrum of intensities in elite rugby union players. RM, Repetition maximum. $\mathrm{n}=26$. *, denotes small to moderate differences (effect size) between $30 \%$ and all other loads. 
Table 1. Order and outline of strength and power assessments.

\begin{tabular}{llll} 
Order & Mode & Exercise & Load \\
\hline Session One & Upper-body strength & Bench press & Maximal \\
Session Two & Upper-body power & Bench throw & 20\%, 30\%, 40\% 1RM bench press \\
Session Three & Upper-body power & Bench throw & 50\%, 60\% 1RM bench press
\end{tabular}

RM, Repetition maximum. Twenty four hours separated each session unless otherwise stated. 